УДК 811.1/8

ББК 81(091)

DOI: https://doi.org/10.17308/lic.2020.3/2945

\title{
ЗАПАДНАЯ КОГНИТИВНАЯ ЛИНГВИСТИКА КАК ЦЕЛОСТНАЯ НАУЧНАЯ ПАРАДИГМА
}

(Рец. на кн.: Evans V. Cognitive linguistics. A complete guide. Second edition. Edinburgh : Edinburgh University Press, 2019. 858 p.)

\author{
К. М. Денисов
}

Российский экономический университет имени Г. В. Плеханова

О. М. Карпова

Ивановский государственный университет

\section{WESTERN COGNITIVE LINGUISTICS AS COHERENT SCIENTIFIC PAR- ADIGM}

\section{(Review of Evans V. Cognitive linguistics. A complete cuide. Second edition. Edinburgh : Edinburgh University Press, 2019. 858 p.)}

\author{
K. M. Denisov \\ Plekhanov Russian University of Economics \\ O. M. Karpova \\ Ivanovo State University
}

\begin{abstract}
Рецензируемая монография является обобщающим трудом известного британского ученого Вивиана Эванса и основана на более раннем труде Cognitive Linguistics: An Introduction (Evans and Green, 2006). Профессор Эванс является международно признанным экспертом по вопросам языка и цифровой коммуникации. Он получил докторскую степень по лингвистике при Джоржтаунском университете в г. Вашингтоне (США) в 2000 г., преподавал в ряде британских университетов (Суссекс, Брайтон и Бангор). Эванс является автором 14 монографий, среди которых наиболее известны: The Emoji Code: The Linguistics Behind Smiley Faces and Scaredy Cats (2017), The Crucible of Language: How Language and Mind Create Meaning (2015), и The Language Myth: Why Language is Not an Instinct (2014).

Профессор Эванс является приверженцем теории Семантического доступа (Access Semantics), или теории лексических концептов и когнитивных моде-
\end{abstract}

лей (ЛККМ), рассматривающей язык в качестве конструктора отраженных концептуальных систем (время, пространство и пр.).

Масштаб рецензируемой монографии впечатляет: текст книги содержит предисловие, пять массивных разделов, расположившихся на 813 страницах текста, обширную библиографию, включающую 720 источников, постраничный индекс использования 878 базовых терминов, 213 рисунков, графов и схем, а также 98 таблиц.

Основной пафос работы, на наш взгляд, заключается в попытке решения стратегической задачи - построения комплексной картины взаимодействия сознания и языка, раскрытия мотивационных механизмов созидания языковых конструктов, непосредственно отражающих церебральные процессы мыслительного, эмотивного и модально-волевого познания окружающего мира и адаптации к нему. Все это рассматривается сквозь призму эволюции языка как

(С) Денисов К. М., Карпова О. М., 2020 
постоянно обретаемого опыта отдельным индивидом и человечеством в целом.

В предисловии к данному, второму изданию книги автор представляет ее как наиболее полный экскурс в историю и современность когнитивной лингвистики - сложившейся, самостоятельной отрасли западного и мирового языкознания. Двумя базовыми установками этого учения В. Эванс считает принципы генерализации (Generalisation Commitment) и когнитивизма (Cognitive Commitment). Они предопределяют теорию и методологию исследования языковой концептуальной структуры, семантики и прагматики, а также подчеркивают связь когнитивной отрасли языкознания со смежными научными дисциплинами, направленными на изучение мозговой деятельности и сознания носителей языка, их социального поведения.

Автор анализирует основополагающие принципы и правила когнитивной лингвистики в их приложении к изучению таких разделов, как семантика, прагматика, фонология и грамматика. Известная часть книги посвящена проблемам герменевтики и невербальной коммуникации. Основной своей задачей профессор Эванс считает создание подробного «путеводителя», целостной и динамичной панорамы функционирования отрасли когнитивной лингвистики на примерах применения современных принципов и методик экспериентализма. В связи с этим каждая из пяти частей книги представляет собой тематическую группировку языковых примеров, используемых для демонстрации дескриптивных возможностей гносеологического арсенала когнитивного языкознания и соответствующих концептуальных обобщений.

Часть І «Отрасль когнитивной лингвистики» отражает идеологию данного направления и содержит 7 глав, каждая из которых является иллюстрацией применения основных принципов и правил когнитивистики, а также противопоставляет когнитивную лингвистику так называемой формальной лингвистике, представленной, прежде всего, постулатами трансформационной грамматики. Поскольку эта часть является установочной и отражает научное мировоззрение когнитивных лингвистов, остановимся на ней чуть подробнее.

Глава 1 «Что изучают когнитивные лингвисты?» является идеологической интродукцией когнитивистики и рассматривает объект и предмет ее исследования. Объектом изучения являются все языковые единицы от морфемы до текста, функционирующие в экспериенталистских фреймах, т. е. интерактивных условиях реализации концептуальной структуры нашего сознания. Из анализа коммуникативного опыта мы черпаем знания о системности, структуре и функциях языка. Язык кодирует и воплощает наши мысли посредством символов, представ- ляющих собой формально-смысловые пары или символические блоки, которые служат репрезентантами концептов.

Концепты являются производными от перцептов - результатов обработки фактов чувственного восприятия. Значения, кодируемые лингвистическими символами, относятся к проектируемой реальности, определяемой как мыслимое представление о реальности, конструируемой нашим сознанием. Поскольку диапазон концептуализаций безграничен, язык предоставляет лишь конструкты для их моделирования.

Символические блоки систематизируются в концептуальные домены, содержанием которых являются идеи и разновидности когнитивного опыта. Таким образом, утверждает автор, языковые структуры предстают как мотивированные и оформленные «рефлексы познания».

Языковые формы являются когнитивными репрезентантами двух основных подсистем языка-лексической и грамматической. Члены первой подсистемы открытого класса воплощают буквальное значение и выполняют содержательную функцию. Элементы второй системы закрытого класса несут идиоматическое значение, выполняя структурирующую функцию. Взаимодействие элементов обоих классов порождает схематическое значение языкового фрейма. Декодирование и дескрипция данных значений, их системная связь с процессами познания и таксономия являются предметом исследования когнитивных лингвистов.

Глава 2 «Ключевые установки и методы исследования» содержит изложение базовых установок: генерализации и когнитивизма. Особый интерес для специалистов представляет описание методов научного исследования: интроспективного, аудио-визуального, корпусного, бихевиористского, нейронаучного.

Глава 3 «Основные положения опыта I: пространство» представляет проекцию частного исследования категории «пространство», предпринятого автором. Восприятие данной категории разделено на фазы: ощущение, перцептивная организация/идентификация и распознавание. Ощущения преобразуются в нейронные коды, распознаваемые мозгом.

Распознавание идет по модальным системам: визуальной, вестибулярной, аудитивной и гаптической. Здесь впервые в книге вводится рекуррентное понятие полимодальности человеческого восприятия. Фаза перцептивной организации состоит из процесса преобразования чувственной информации в единый объект сознания - перцепт. Предварительно сформированный концепт распознает, идентифицирует и классифицирует перцепт как категорию, которая в результате обработки встраивается в концептуальную систему. Автономность концепта обеспечивается 
применением гештальт-принципа, состоящего в мысленном перемещении образа предмета с заднего плана на переднее поле (в светлую точку) сознания.

В. Эванс уделяет большое внимание пространственным схемам на примере их составных конструктов (элементов закрытых классов слов), в данном случае английских предлогов. Данное исследование, как, впрочем, и многие другие примеры частных исследований, приведенных в книге, ценны для нас в качестве опыта глубинной интерпретации функционирования морфосинтаксических элементов носителем языка.

Пространственные схемы анализируются в терминах их пространственно-геометрических компонентов, свойств этих компонентов и отношений между ними. Автор анализирует фреймы пространственной референции (ФПР) - системы координат, включающие фигуру, объект и начальную точку референции, а также специфику кроссязыковых репрезентаций категории «пространство».

Глава 4 «Основные положения опыта I: время» содержит таксономию ФВР - фреймов временной референции, как на примере английского языка, так и языков юго-восточной Азии. Рассматривается матрица концепта «время» в прямом (темпоральном) аспекте лексического значения слова и в ракурсе теории концептуальной метафоры. Анализируются параметрические концепты направленности, протяженности, последовательности, мимолетности. Инновационным представляется взгляд автора на видовременную семантику глагольных форм, который получает развитие в последующих главах монографии.

Глава 5 «Практика языка I: знание о языке» начинает полемику с менталистской концепцией языковой компетенции. Приводятся три составляющие узуального базиса языка, принятого в когнитивной лингвистике: а) учение о высказывании; б) учение об узусе как источнике знания о языке; в) учение об интерактивной природе языковой практики; г) учение о контексте; д) учение об относительной частотности языковых единиц как основной характеристике природы языковых систем.

Названные аспекты рассматриваются автором в разрезе узуальной модели - когнитивной грамматики Рональда Ла́нгакера. Эта модель противопоставляется модели трансформационной грамматики Наума Хомского. Модель Ла́нгакера определяет лингвистические единицы как символические блоки, напрямую выводимые из языковой практики посредством процесса абстрагирования, результатом которого является создание схем.

Глава 6 «Практика языка II: усвоение языка и языковые изменения» представляет собой анализ двух алгоритмов: алгоритма языковой изменчивости (теория выбора высказываний Крофта) и алгоритма усвоения языка (психолингвистическая теория Томаселло). Автор демонстрирует процесс форсайтного развития языковых форм через возможность альтернативного воспроизведения, закрепления и отбора формально-смысловых комплексов. Это, по его мнению, приводит к принятию новых языковых конвенций и, соответственно, стратегическим изменениям в языке.

Далее профессор Эванс вслед за Майклом Томаселло утверждает, что усвоение языка уже в раннем возрасте происходит не на основании правил (rules), а на основании непосредственных данностей (items). Данный узуальный навык формирует у индивида объединенные фреймы внимания (ОФВ), облегчающие имитацию языкового поведения, что в свою очередь становится устойчивой формой культурного познания, которое в своей основе носит характер символического конструирования.

Глава 7 «Ключевые дискуссионные вопросы языкознания: формальная лингвистика в противовес когнитивной лингвистике» завершает первую часть книги. В ней автор приводит подробную дискуссию двух ведущих западных школ языкознания.

Согласно постулатам формальной лингвистики, представленной в книге работами Наума Хомского и Джерри Фодора, язык как некая генетическая мутация появляется у человека сравнительно недавно в виде качественного скачка (сальтации) и коренится в формальных моделях. Язык скорее необходим как универсальный инструмент для выражения мысли, а не для коммуникации. При этом подчеркивается жесткая модульность сознания.

Когнитивная лингвистика, в противовес сказанному, постулирует тезис экспериентального реализма, согласно которому не существует врожденной биологической предопределенности языка. Язык происходит из приобретенного опыта как межотраслевая сущность познания, имеющая не скачкообразную, а длительную градуально-эволюционную историю. Язык, формируемый и очерченный общностью воплощенного познания, - это особая ниша общения, свойственная человеку как биокультурному виду. Языковая коммуникация является источником универсального концептуального пространства, в котором языки располагаются в виде специфических семантических навигационных карт, иногда сходящихся в общих точках. Актуальной в этой связи является переосмысленная когнитивными лингвистами теория языкового релятивизма Сэпира - Уорфа, согласно которой язык приводит к когнитивной реструктуризации, т. е. язык влияет на мысль и сознание в целом.

Часть II «Концептуальная структура» раскрывает представление автора о концептуальной струк- 
туре как субстрате, помещенном в человеческую концептуальную систему, обслуживающую язык и мышление. Язык отражает природу, структуру и организацию мысли, раскрывая окно в мир человеческого сознания и воплощенного опыта.

Две базовые установки когнитивной лингвистики включают два главных гносеологических принципа, которые способствуют осмыслению концептуальной структуры. Первый принцип - это тезис о воплощенности концептуальной структуры, известный также под названием «тезис воплощенного сознания». Второй принцип состоит в том, что семантическая структура (значения, кодируемые языком) отражает концептуальную структуру. Иллюстративным материалом применения этих принципов служат главы, посвященные таким явлениям, как образные схемы, концептуальные метафоры, категоризация и метонимия.

Часть III «Семантическая структура» постулирует энциклопедический характер семантической структуры. Энциклопедический взгляд на семантику способствует, по мнению автора, созданию симуляций или динамических моделей сознания, активизирующих процессы мультимодального воплощенного опыта, опосредованного языком. На различных примерах реконструкции и анализа значения языковых единиц профессор Эванс демонстрирует явления энциклопедической семантики, ментального пространства, сложных концептуальных слияний, а также рассматривает частные вопросы формирования лексического и композиционно-грамматического значения.

Часть IV «Грамматика» затрагивает проблему природы грамматических явлений с точки зрения когнитивного лингвиста. Традиционно выделяемые языковые формы (фонологические, морфологические и синтаксические) сопоставляются со значением в контексте их символической природы. Подробный экскурс в область происхождения, историю и современное состояние языковых единиц, проведенный автором, позволяет нам увидеть инновационную трактовку лексико-грамматических и морфосинтаксических явлений, основанную на когнитивных принципах. Эта трактовка отличается от воззрений представителей традиционной, структуралистской и трансформационной грамматик.

Прежде всего, это касается грамматических явлений, категорий и субкатегорий (имманентная грамматикализация лексико-грамматического континуума, темпоральные и атемпоральные отношения, мотивационные созначения, модель акциональных цепочек, атрибутивная версия вербалий, эпистемология видо-временных отношений, валентно-семантические домены, предикативные схемы и многое другое).
Привлекает внимание статья 27, посвященная эволюции взаимодействия синхронии и диахронии в процессе более детального и глубинного анализа грамматических явлений языка с точки зрения таких лингвокогнитивных теорий и таких подходов, как идея метафорического расширения, учение об уровневой полисемии, теорий субъектификационного конструирования, прагматической инференции и кодификации и др.

Часть V «Применение и распространение когнитивного языкознания» посвящена освещению процесса проникновения когнитивной теории и методологии в такие сферы познания, как социальное поведение, дискурсивная практика, языковая вариативность и диалектология, мультимодальная коммуникация, невевербальная коммуникация, текстология и герменевтика, когнитивная поэтика. В. Эвансу, безусловно, удается в отдельных главах, посвященных каждой из названных тем, соблюсти баланс между теоретическими постулатами и практическим анализом явлений в русле избранных методик.

В целом, книга напоминает построение рондо - в каждой из глав автор возвращается к принципам генерализации и когнитивизма, основным правилам и методикам, применяя их при конструировании конкретных процедур, моделей и схем анализа различных явлений и параметров дискурса. В ткань работы вплетены как рассмотрение достижений его предшественников, так и результаты собственных исследований В. Эванса в русле когнитивной лингвистики, проводимых автором на протяжении более двадцати последних лет. Они включают: раскрытие смысла основополагающих доменов пространства и времени в структуре человеческого опыта (главы 3 и 4), вклад в развитие подходов когнитивной лингвистики к исследованию лексической семантики (глава 17) и композиционной семантики слова (глава 18).

Наряду с бесспорным теоретическим, исследовательским и справочно-информационным значением рецензируемой книги следует отметить ее образовательную ценность. Разделы книги, посвященные анализу лингвистических явлений, снабжены вопросами для обсуждения и закрепления прочитанного. Использование этих материалов в курсах лекций по лексикологии, семасиологии, грамматике, фонологии, психолингвистике, социолингвистике и невербальной коммуникации может быть расширено с помощью образовательной платформы университета Эдинбурга (edinburghuniversitypress.com/cognitivelinguistics), содержащей большое количество упражнений, которые можно загрузить онлайн для работы на тематических семинарах и практикумах.

Обширная терминология, накопленная за более чем полувековую историю развития когнитивной лингвистики, представлена как в тексте монографии, 
так и в сопряженном с книгой алфавитном глоссарии - Glossary of Cognitive Linguistics (Evans 2007). Причем предложенный автором глоссарий является первой и удачной попыткой систематизировать англоязычный терминологический аппарат когнитивной лингвистики и снабдить исследователя подробным толкованием не только общих, но и узкоспециальных терминов, которые ранее не включались в подобные справочники.

Книга, по мнению самого автора, рассчитана не только на профессионалов, но и на тех, для кого она может стать путеводителем по увлекательному

Российский экономический университет имени Г. В. Плеханова

Денисов К. М., кандидат филологических наук, доиент

E-mail:bondin5@yahoo.com

Ивановский государственный университет

Карпова О. М., доктор филологических наук, профессор, заведуюшая кафедрой английской филологии

E-mail: olga.m.karpova@mail.ru

Поступила в редакичию 14 марта 2020 г.

Принята к публикачии 15 июня 2020 г.

\section{Для цичтирования:}

Денисов К. М., Карпова О. М. Западная когнитивная лингвистика как целостная научная парадигма (Рец. на кн.: Evans V. Cognitive linguistics. A complete guide. Second Edition. Edinburgh : Edinburgh University Press, 2019. 858 р.) // Вестник Воронежского государственного университета. Серия: Лингвистика и межкультурная коммуникация. 2020. № 3. C. 147-151. DOI: https://doi. org/10.17308/lic.2020.3/2945 лабиринту современного языкознания, наполненному неожиданными и захватывающими открытиями.

Необходимо отметить, что рецензируемая монография прошла апробацию на курсе «Когнитивная лингвистика и когнитивное терминоведение» для магистров по специальности 45.04.01 Филология (зарубежная филология) на факультете романо-германской филологии Ивановского государственного университета осенью 2019 г. и стала дополнительным источником новых сведений по современной зарубежной когнитивной лингвистике.

Plekhanov Russian University of Economics

Denisov K. M., Candidate of Philology, Associate Professor

E-mail: bondin5@yahoo.com

Ivanovo State University

Karpova O. M., Doctor of Philology, Professor, Head of the English Philology Department

E-mail: olga.m.karpova@mail.ru

Received: 14 March 2020

Accepted: 15 June 2020

\section{For citation:}

Denisov K. M., Karpova O. M. Western cognitive linguistics as coherent scientific paradigm (Review of Evans V. Cognitive linguistics. A complete cuide. Second edition. Edinburgh : Edinburgh University Press, 2019. 858 p.). Proceedings of Voronezh State University. Series: Linguistics and Intercultural Communication. 2020. No. 3. Pp. 147-151. DOI: https://doi.org/10.17308/lic.2020.3/2945 